\title{
Thoracic endovascular aortic repair for type A aortic dissection: a promising option for inoperable patients
}

\author{
Gregory P. Boyajian^, Anahita Ghazi, Irina Kolesnik, Shahab Toursavadkohi, Mehrdad Ghoreishi, \\ Bradley Taylor \\ University of Maryland School of Medicine, Baltimore, MD, USA \\ Contributions: (I) Conception and design: GP Boyajian, M Ghoreishi, B Taylor, S Toursavadkohi; (II) Administrative support: A Ghazi, I Kolesnik; \\ (III) Provision of study material or patients: None; (IV) Collection and assembly of data: None; (V) Data analysis and interpretation: None; (VI) \\ Manuscript writing: All authors; (VII) Final approval of manuscript: All authors. \\ Correspondence to: Gregory P. Boyajian. University of Maryland School of Medicine, Baltimore, MD, USA. Email: gregoryboyajian@gmail.com.
}

\begin{abstract}
Acute type A aortic dissection (AAAD) is a surgical emergency that carries a grave prognosis if not diagnosed early and treated rapidly. The standard of care for patients presenting with AAAD is median sternotomy and open surgical repair of the ascending aorta. However, many patients with AAAD are determined to be too high-risk for open surgery due to malperfusion, shock, advanced age, or severe comorbidities. Inoperable patients are traditionally managed medically and experience high mortality. In recent years, the use of Thoracic Endovascular Aortic Repair (TEVAR) as an endovascular option for otherwise inoperable patients has been reported by several major aortic centers across the globe. Operative mortality in patients receiving TEVAR for $\mathrm{AAAD}$ is superior to conservative medical management only. Long-term follow-up data is limited, but early case series have reported positive outcomes, favorable aortic remodeling, and few complications. The anatomic features of the ascending aorta and lack of a commercial graft designed specifically for deployment in this area are the major challenges to this treatment approach. In this review article, we summarize the current state of ascending TEVAR for AAAD repair, explain our own methodology for patient selection and surgical technique, and discuss the future direction of endovascular repair of AAAD in "inoperable" patients.
\end{abstract}

Keywords: Cardiac surgery; inoperable; dissection; thoracic endovascular aortic repair (TEVAR)

Received: 07 May 2020; Accepted: 29 July 2020; Published: 20 October 2021.

doi: 10.21037 /jovs-20-127

View this article at: http://dx.doi.org/10.21037/jovs-20-127

\section{Introduction}

Acute type A aortic dissection (AAAD) is a surgical emergency that requires rapid intervention, as unrecognized or untreated AAAD carries high rates of mortality (1-4). Although the standard treatment is open surgical repair, up to $20 \%$ of patients presenting with AAAD are determined to be too high-risk for open surgery $(5-10)$. Conservative management for patients with acute type A dissection is associated with poor outcomes $(>70 \%$ mortality within 30 days) $(3,11)$. The advent of endovascular aortic intervention has introduced a new solution for patients who are too high-risk for open surgery. In this article, we review the recent literature on thoracic endovascular aortic repair (TEVAR) as an intervention in the ascending aorta, and discuss our experience using TEVAR as an alternative to medical therapy in "inoperable" patients.

\section{Advent of an endovascular approach for high risk patients}

In 2000, Dorros et al. pioneered the endovascular approach for ascending aortic repair when he conducted a transseptal graft placement utilizing a right femoral vein

$\wedge$ ORCID: 0000-0002-1295-7307. 
approach (12). The first endovascular ascending aortic stent placed via arterial approach followed shortly thereafter, in 2003 (13). Since that time, several institutions have utilized endovascular interventions for patients with ascending aortic disease who are high risk for operative mortality. A review of 46 manuscripts found that between 2000 and 2017, at least 118 patients with ascending aortic pathology have been managed with a primary endovascular approach. These patients were treated with thirteen different types of aortic stent grafts; the most commonly used device types were commercial thoracic stents, abdominal cuffs, and custom-made grafts. Although average follow-up time was just 17.2 months, all-cause mortality in this analysis was $15.2 \%$ and aortarelated mortality was $5 \%$ (14). Since the publication of this review in 2018, there have been at least four additional case reports or case series published on the topic of endovascular repair of the ascending aorta (including our series of 13 patients treated in 2018 and 2019) $(6,15-17)$. While knowledge is currently limited by small, singleinstitution case series and a lack of long-term follow-up data, initial reports of endovascular repair of the ascending aorta in high-risk patients have yielded low mortality and excellent results (6,17-19).

\section{Patient selection-distinguishing high risk from prohibitive risk}

Accurate preoperative risk stratification is a critical first step in identifying patients who are at high risk for operative mortality. Roselli et al. reviewed 686 patients who presented with acute type A dissection between 2005 and 2015 and identified fifty-three patients $(7.7 \%)$ who were determined to be inoperable. His team then conducted chart review and active follow-up in order to determine the specific reasons why patients were deemed inoperable. This allowed the authors to distinguish between "high risk" inoperable patients (who were potential candidates for endovascular repair) and "prohibitive risk" inoperable patients (who were unfit for any intervention, including endovascular repair). Patients with comorbid dementia, advanced malignancy, severe malperfusion, and severe stroke were classified as prohibitive risk due to their high likelihood of mortality regardless of the outcome of their aortic disease. The authors determined that 18 out of 53 inoperable patients (34\%) had a prohibitive risk for any intervention, but 35 of the 53 inoperable patients (66\%) may have been suitable for endovascular stent grafting. Detailed imaging analysis was also conducted to assess the morphology of the ascending aorta and the feasibility of endovascular stent grafting. This analysis showed that intimal entry tears most frequently occurred in a portion of the ascending aorta that could be covered with an endovascular device (5).

Rampoldi et al. utilized data from the International Registry of Acute Aortic Dissection (IRAD) to generate a risk prediction tool based on numerous independent predictors of surgical death: age equal to or greater than 70 years, aortic rupture with preoperative hypotension, shock or cardiac tamponade, signs of acute myocardial ischemia or infarction, and intraoperative cardiac dysfunction. Review of IRAD data has also shown that unstable patients experience double the rate of surgical mortality than stable patients $(7,10)$. Recently, Ghoreishi et al. developed a novel risk score based on elevations in pre-operative laboratory values: lactic acid, creatinine, AST, ALT, and bilirubin. This score allows stratification of patients with AAAD into one of three operative mortality risk categories-mild (4\% risk), moderate (14\% risk) and high (37\% risk). At the University of Maryland, we utilize this risk score to identify patients at high risk for operative mortality because the lab values are easily obtained in all patients, and the score itself is both objective and accurate. We consider endovascular repair of the ascending aorta in the high risk category if anatomy is suitable.

\section{Endovascular repair technique}

Endovascular repair of ascending aortic dissection should begin with classification of the entry tear according to zones described by Dr. Roselli and colleagues: zone 0A (AV annulus to coronary arteries), zone 0B (coronary arteries to right pulmonary artery), and zone 0C (right pulmonary artery to innominate artery) (Figure 1) $(9,20)$. Computed tomography (CT) images used in conjunction with 3-dimensional imaging software (Terarecon, San Mateo, CA, USA) are the appropriate tools to identify the location and length of the dissection flap, measure the aortic diameter, and measure the distance from the highest coronary to the origin of the innominate artery (both along the greater curvature and along a constructed central line) (Figure 2).

We perform all procedures in a hybrid operating room, and a multidisciplinary team consisting of a cardiac surgeon, vascular surgeon, interventional cardiologist, and cardiac perfusion team are present for the duration of the operation. The common femoral artery is accessed percutaneously 
and systemic heparinization is initiated with an activated clotting time goal of $>250$ seconds. Next, temporary pacing wires are inserted, either through the common femoral vein or the right internal jugular vein. A pigtail catheter is placed in the contralateral femoral artery for angiography. Prior to stent deployment, intravascular ultrasound (IVUS) is used to visualize the entire aorta, confirm the location

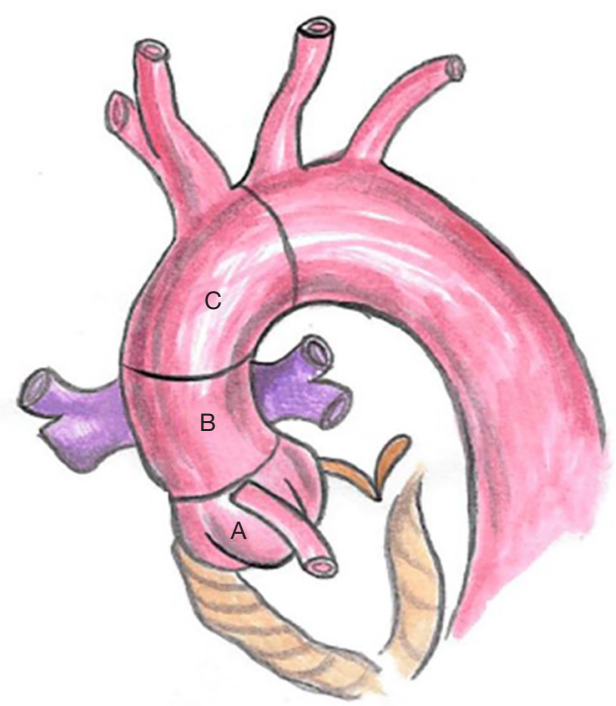

Figure 1 Subdivisions of Zone 0 as defined by Roselli et al., Zone 0A (annulus to coronary), Zone 0B (coronary through right pulmonary artery), and Zone $0 \mathrm{C}$ (right pulmonary artery through innominate). of the entry tear, and verify the placement of wires in the true lumen throughout the aorta. The $\mathrm{AV}$ is then crossed with the use of an AL1 catheter and a straight tip 0.035 wire, which is then positioned in the left ventricle. A transfemoral endograft device is then inserted over the stiff wire and positioned in the ascending aorta. At this point, angiography should be performed to assess the coronary arteries, innominate artery, and dissection location. Upon positioning of the device in the appropriate location, rapid ventricular pacing is conducted to drop the Mean Arterial Pressure into the range of $40-50 \mathrm{mmHg}$, and the device is deployed. Following deployment, a completion angiogram should be performed to re-assess the coronary arteries and arch vessels, as well as to evaluate possible endoleak and AV insufficiency (Figure 3 and Figure 4, Video 1) (6).

\section{Mortality outcomes of endovascular repairs}

In our initial series, operative mortality was $15.4 \%$ ( 2 of 13 ) (operative mortality was defined as any in-hospital mortality or death within 30 days of procedure) (6). Neither of these two deaths were attributable to aortic etiology-one patient died due to a large intracranial hemorrhage, and the other was a patient with a long history of severe right ventricular failure who experienced lethal dysrhythmia following rapid ventricular pacing. Our mortality statistics are comparable with the all-cause mortality of $15.2 \%$ reported in the Muetterties et al. systematic review, as well as 30-day mortality rates reported by Roselli et al. (13.6\%) and Preventza et al. (14.3\%) $(14,21,22)$. When compared to
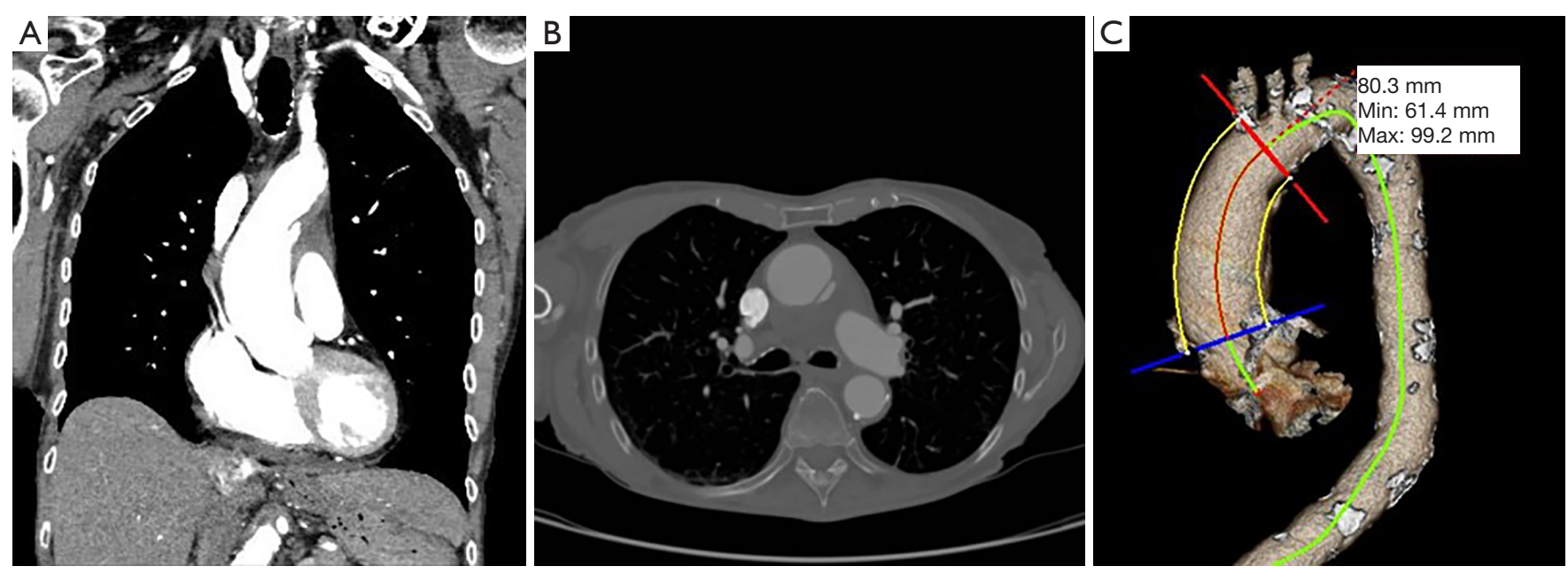

Figure 2 Preoperative CTA showing zone 0B intimal tear (A and B), and a 3D reconstruction with centerline, greater curvature, and lesser curvature measurements (C). 

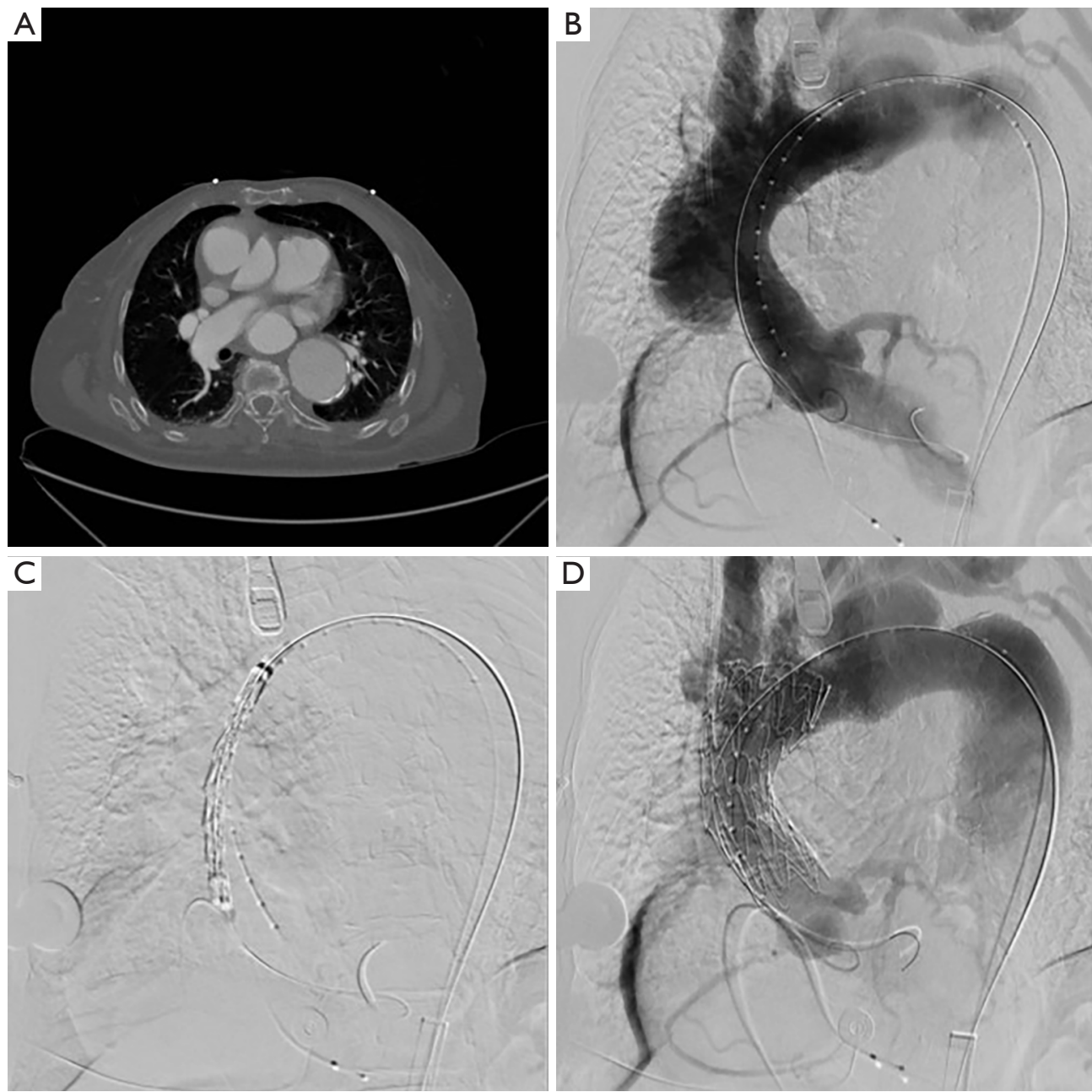

Figure 3 Pre-operative CTA and intra-operative angiography showing Zone 0B dissection with aneurysmal dilation (A and B). The stent is positioned in the ascending aorta (B). Following successful deployment of the stent, contrast fills the true lumen and perfusion of the head vessels and coronary arteries remains intact $(\mathrm{CD})$.

mortality statistics garnered from the IRAD, endovascular repair of AAAD is as safe as open surgical repair $(26 \%$ inhospital mortality) or medical management alone (58\% inhospital mortality) (11).

\section{Postoperative follow up}

Follow-up for ascending aorta TEVAR patients should include regular CT scans, preferably at 1-month postoperation, 3-months post-operation, and then regular 6-month intervals. The primary goal of postoperative follow-up is to evaluate the safety of ascending endovascular repair. The secondary objectives are to evaluate for endoleak, aortic remodeling, and stent migration.

\section{Endoleak}

Many centers have observed endoleak following TEVAR for AAAD. Treatment is patient-specific and has ranged from expectant management to endovascular reoperation or open repair $(14,18,21)$. In our experience, endoleak occurred in 3 of 22 patients $(13.6 \%)$ and was most common in patients with zone $0 \mathrm{~A}$ dissections. This is likely because there is no commercial device specifically designed for deployment in zone 0A. One patient with zone 0A disease had a small residual endoleak on CT scan prior to discharge that remained stable at the 1 -month follow-up CT scan. On the 6-month follow-up CT scan, the endoleak was resolved and the ascending aorta 

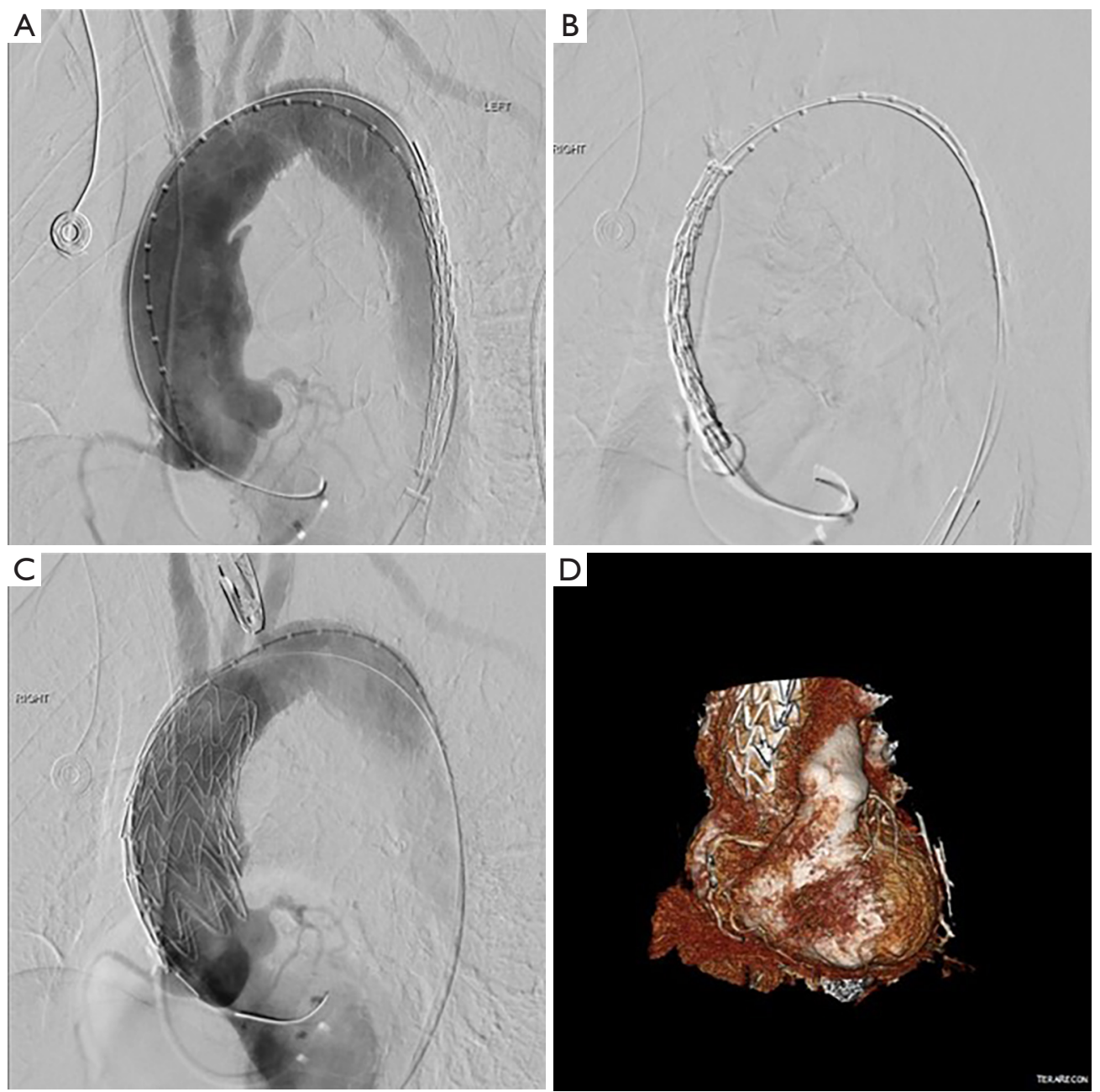

Figure 4 Intra-operative angiography showing Zone 0B intimal tear with filling of the false lumen (A). The stent is positioned in the ascending aorta (B). Following successful deployment of the stent, contrast fills the true lumen and perfusion of the head vessels and coronary arteries remains intact (C). A post-op 3D reconstruction shows the deployed stent (D).

had favorably remodeled (6). This case illustrates the utility of expanding the true lumen with endovascular stenting to capture as much flow as possible and limit further expansion of the false lumen, even if the device cannot cover the intimal tear completely. Our approach to small residual endoleak in asymptomatic patients is to manage medically and ensure close follow-up (Figure 5). Reoperation to correct endoleak was not necessary.

\section{Aortic remodeling}

Evidence of aortic remodeling on CT scan is an important indicator of therapeutic success (Figure 6). At this time, two case series have reported favorable aortic remodeling following endovascular intervention in the ascending aorta. Ghoreishi et al. described evidence of favorable aortic remodeling in a cohort with a median follow-up time of 13 months (6). Li et al. also reported favorable aortic remodeling in a cohort with a median follow-up interval of 71 months. Follow-up imaging analysis showed complete thrombosis of the false lumen in the ascending aorta and either complete or partial thrombosis of the false lumen in the descending aorta in all DeBakey Type I patients. The only patient in which aortic remodeling failed was a patient with DeBakey Type II dissection who was later converted to an open repair with replacement of the ascending aorta (18). 


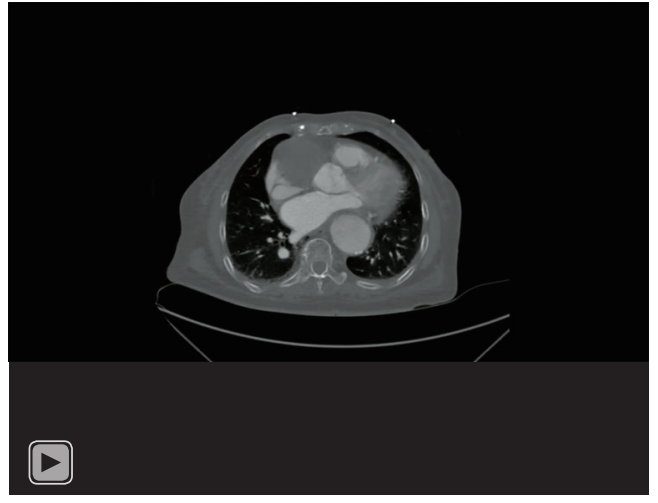

Video 1 Two cases of ascending TEVAR for primary repair of acute type A dissection. Pre-operative and post-operative CT scans are included to demonstrate the location of the intimal tear and final position of the stent grafts.

\section{Stent migration}

Reports of stent migration in short-term follow-up are rare-a systematic review of endovascular intervention for any ascending aortic pathology found that stent migration occurred in only two patients out of 118 (1.7\%) (14). One of these patients was asymptomatic following pseudoaneurysm repair, but was incidentally discovered to have distal stent migration on 6-month follow-up CT. He had since recovered from acute illness, so an elective open device retrieval was performed (21). It is important to note that there is no long-term follow-up data on TEVAR for ascending aortic repair. Therefore, stent migration will be a chief area of interest in future reports of ascending aortic TEVAR outcomes.
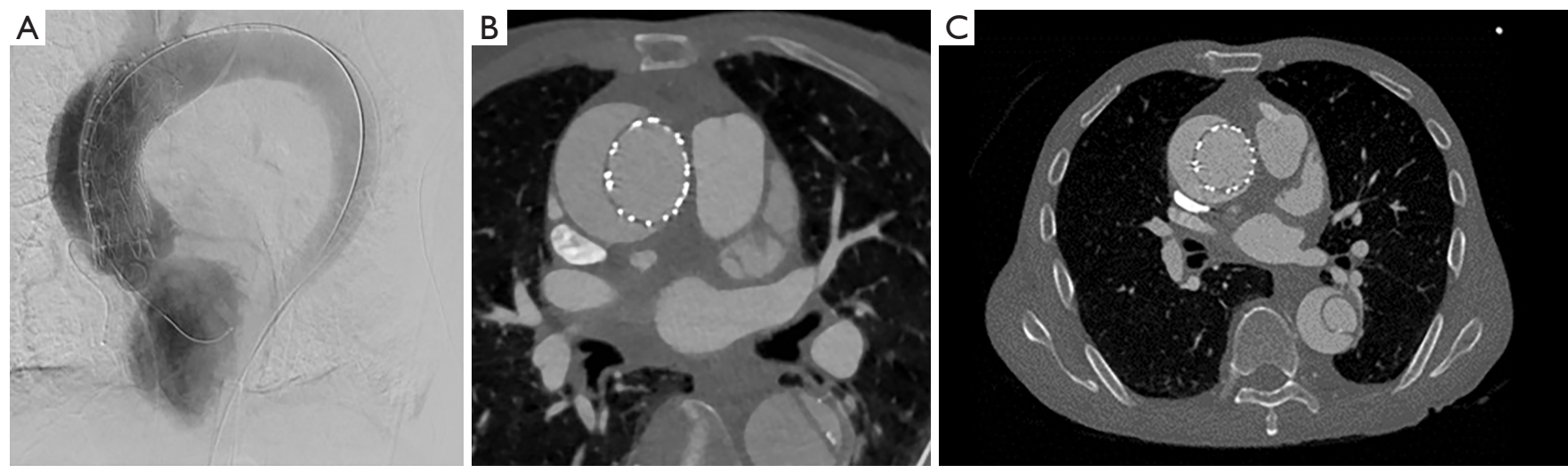

Figure 5 Endoleak demonstrated post-graft deployment in a patient with zone 0A intimal tear (A). The endoleak remained stable at one week post-op (B), and at four months post-op (C).
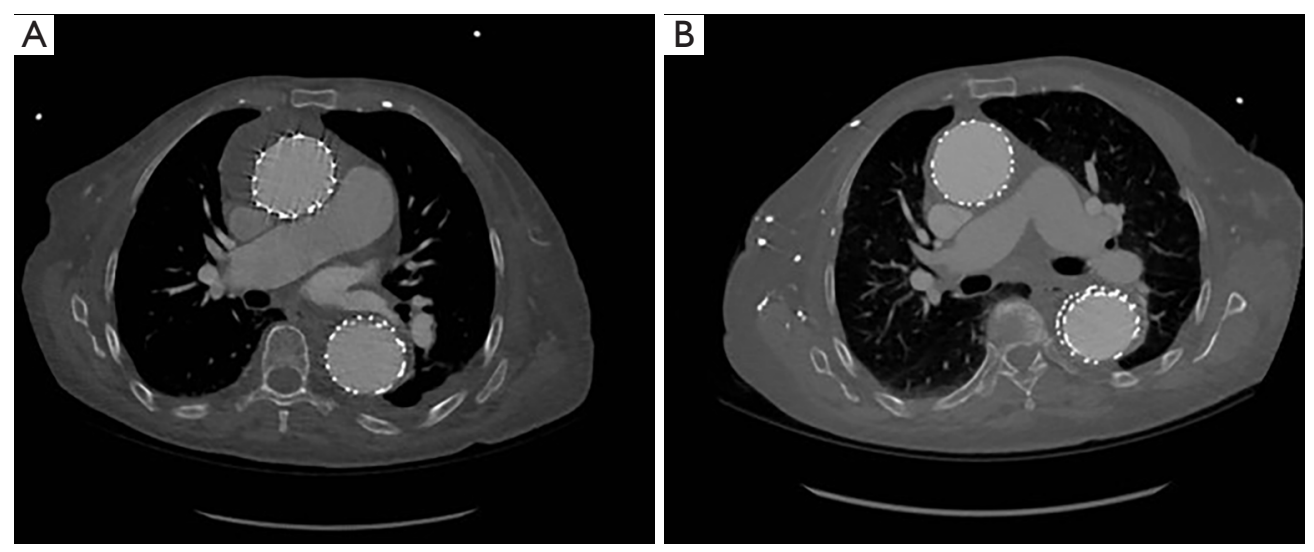

Figure 6 This is a TEVAR for Zone $0 \mathrm{~B}$ dissection that extended into the aortic arch and descending thoracic aorta. CT scans are shown at three months post-op (A), and eight months post-op (B). 


\section{Intraoperative and postoperative complications}

Major intraoperative complications during endovascular repair of the ascending aorta have been rarely described. At our center, one patient sustained a refractory arrhythmia following rapid ventricular pacing and did not recover (6). Overdrive pacing is utilized by many centers as a method to decrease aortic blood velocity and temporarily induce hypotension during deployment of a stent in the ascending aorta, but the necessity of this practice is not clear and should be investigated further $(16,17,19,23)$. Another intraoperative challenge to TEVAR efficacy in ascending aortic disease is friable aortic tissue-most notable seen in patients with intramural hematoma. These patients are at high risk of aortic rupture with any endovascular therapy. A variety of post-operative complications have been described by several centers: post-operative stroke, femoral artery dissection, pericardial effusion/hemopericardium, bleeding, and pneumonia $(6,18,24)$. The most common complication associated with primary endovascular repair of the ascending aorta is endoleak, which was found to occur in $18.6 \%$ of published cases between 2000 and 2017 (14). More recent case series continue to report endoleak as a significant concern, and it was the cause of at least one operative mortality $(6,24)$.

\section{Challenges to endovascular repair of the ascending aorta}

Endovascular intervention in the ascending aorta has multiple challenges. The descending aorta endovascular repair standard of a $2-\mathrm{cm}$ landing zone in healthy tissue is difficult to apply to the ascending aorta due to its short length, curvature, and the proximity of the coronary arteries, aortic valve, and innominate artery $(6,14)$. If the intimal tear occurs in zone $0 \mathrm{~A}$ (aortic root), a $2-\mathrm{cm}$ proximal landing zone would compromise the aortic valve leaflets (9). Therefore, some patients may not be candidates for endovascular repair due to absence of a suitable proximal landing zone. This will continue to be a major limitation in endovascular ascending aorta repair until the commercial availability of a combined ascending endograft/aortic valve $(16,18,24)$. Certain techniques exist to improve the distal landing zone, such as cervical debranching or extending the endovascular repair with a fenestrated or branched arch endograft $(6,16,17,24)$.

An additional challenge to endovascular ascending aortic repair is the lack of commercially available grafts that are designed specifically for the ascending aorta. While abdominal aortic grafts have been used in an offlabel manner, the ascending aortic segment has higher pulsating motion of the aortic wall than the abdominal aorta, which makes stable fixation of the stent graft more challenging (18). Furthermore, the abdominal aorta grafts are not adequately conformable to the curvature of the ascending aorta, and they have a long nose cone that often must cross the aortic valve for deployment $(6,9)$. Graft selection and sizing is an issue discussed by every major case series on this topic, and the respective authors provide adequate data on which devices they have employed in different situations $(5,6,9,13,14,16-18,23,24)$. W.L. Gore \& Associates is currently testing a thoracic branch endoprosthesis designed specifically for treatment of Zone 0 and Zone 1 aortic lesions. This trial was first submitted in May of 2016 and is currently in the recruitment phase (25). At the University of Maryland Medical Center, we utilize $10 \mathrm{~cm}$ TEVAR stent grafts [Gore TAG (CTAG); W.L. Gore \& Associates, Flagstaff, AZ] for type A aortic dissection, although we have also used proximal aortic extender cuff grafts for ascending aortic dissections with a small entry tear, or for pseudoaneurysm.

\section{Conclusions}

Early reports of endovascular interventions for patients with ascending aortic pathology show that TEVAR is a feasible alternative to medical therapy in high risk patients. Although long-term follow-up data is limited, short-term statistics show that the use of TEVAR instead of medical therapy alone may preserve and prolong life. The ascending aorta presents several unique anatomical challenges to endovascular intervention, and the advent of a commercial device specifically designed for the ascending aorta would make endovascular therapy a more broadly utilized practice.

\section{Acknowledgments}

Funding: None.

\section{Footnote}

Provenance and Peer Review: This article was commissioned by the Guest Editors (Ibrahim Sultan and George Arnaoutakis) for the series "Advancement in the Surgical Treatment of Aortic Dissection" published in Fournal of 
Visualized Surgery. The article has undergone external peer review.

Conflicts of Interest: All authors have completed the ICMJE uniform disclosure form (available at https://jovs. amegroups.com/article/view/10.21037/jovs-20-127/coif). The series "Advancement in the Surgical Treatment of Aortic Dissection" was commissioned by the editorial office without any funding or sponsorship. BT reports personal fees from W. L. Gore, personal fees from Terumo Aortic, outside the submitted work. The authors have no other conflicts of interest to declare.

Ethical Statement: The authors are accountable for all aspects of the work in ensuring that questions related to the accuracy or integrity of any part of the work are appropriately investigated and resolved.

Open Access Statement: This is an Open Access article distributed in accordance with the Creative Commons Attribution-NonCommercial-NoDerivs 4.0 International License (CC BY-NC-ND 4.0), which permits the noncommercial replication and distribution of the article with the strict proviso that no changes or edits are made and the original work is properly cited (including links to both the formal publication through the relevant DOI and the license). See: https://creativecommons.org/licenses/by-nc-nd/4.0/.

\section{References}

1. Evangelista A, Isselbacher EM, Bossone E, et al. Insights from the international registry of acute aortic dissection: A 20-year experience of collaborative clinical research. Circulation 2018;137:1846-60.

2. Mészáros I, Mórocz J, Szlávi J, et al. Epidemiology and clinicopathology of aortic dissection: A population- based longitudinal study over 27 years. Chest 2000;117:1271-8.

3. Melvinsdottir IH, Lund SH, Agnarsson BA, et al. The incidence and mortality of acute thoracic aortic dissection: Results from a whole nation study. Eur J Cardiothorac Surg 2016;50:1111-7.

4. Clouse WD, Hallett JW, Schaff H V., et al. Acute Aortic Dissection: Population-Based Incidence Compared with Degenerative Aortic Aneurysm Rupture. Mayo Clin Proc 2004;79:176-80.

5. Roselli EE, Hasan SM, Idrees JJ, et al. Inoperable patients with acute type A dissection: Are they candidates for endovascular repair? Interact Cardiovasc Thorac Surg
2017;25:582-8.

6. Ghoreishi M, Shah A, Jeudy J, et al. Endovascular Repair of Ascending Aortic Disease in High-Risk Patients Yields Favorable Outcome. Ann Thorac Surg 2020;109:678-85.

7. Rampoldi V, Trimarchi S, Eagle KA, et al. Simple Risk Models to Predict Surgical Mortality in Acute Type A Aortic Dissection: The International Registry of Acute Aortic Dissection Score. Ann Thorac Surg 2007;83:55-61.

8. Trimarchi S, Eagle KA, Nienaber CA, et al. Role of age in acute type A aortic dissection outcome: Report from the International Registry of Acute Aortic Dissection (IRAD). J Thorac Cardiovasc Surg 2010;140:784-9.

9. Roselli EE, Idrees JJ, Johnston DR, et al. Zone zero thoracic endovascular aortic repair: A proposed modification to the classification of landing zones. J Thorac Cardiovasc Surg 2018;155:1381-9.

10. Trimarchi S, Nienaber CA, Rampoldi V, et al. Contemporary results of surgery in acute type a aortic dissection: The International Registry of Acute Aortic Dissection experience. J Thorac Cardiovasc Surg 2005;129:112-22.

11. Hagan PG, Nienaber CA, Isselbacher EM, et al. The International Registry of Acute Aortic Dissection (IRAD): new insights into an old disease. JAMA 2000;283:897-903.

12. Dorros G, Dorros AM, Planton S, et al. Transseptal guidewire stabilization facilitates stent-graft deployment for persistent proximal ascending aortic dissection. J Endovasc Ther 2000;7:506-12.

13. Wang ZG, Massimo CG, Li M, et al. Deployment of endograft in the ascending aorta to reverse type A aortic dissection. Asian J Surg 2003;26:117-9.

14. Muetterties CE, Menon R, Wheatley GH. A systematic review of primary endovascular repair of the ascending aorta. J Vasc Surg 2018;67:332-42.

15. Plichta RP, Hughes GC. Thoracic endovascular aortic repair for the ascending aorta: experience and pitfalls. J Vis Surg 2018;4:92.

16. Tsilimparis N, Drewitz S, Detter C, et al. Endovascular Repair of Ascending Aortic Pathologies With Tubular Endografts: A Single-Center Experience. J Endovasc Ther 2019;26:439-45.

17. Piffaretti G, Grassi V, Lomazzi C, et al. Thoracic endovascular stent graft repair for ascending aortic diseases. J Vasc Surg 2019;70:1384-1389.e1.

18. Li Z, Lu Q, Feng R, et al. Outcomes of Endovascular Repair of Ascending Aortic Dissection in Patients Unsuitable for Direct Surgical Repair. J Am Coll Cardiol 2016;68:1944-54. 
19. Vallabhajosyula P, Gottret JP, Bavaria JE, et al. Endovascular repair of the ascending aorta in patients at high risk for open repair. J Thorac Cardiovasc Surg 2015;149:S144-50.

20. Ghoreishi M, Sundt TM, Cameron DE, et al. Factors associated with acute stroke after type A aortic dissection repair: An analysis of the Society of Thoracic Surgeons National Adult Cardiac Surgery Database. J Thorac Cardiovasc Surg 2020;159:2143-2154.e3.

21. Roselli EE, Idrees J, Greenberg RK, et al. Endovascular stent grafting for ascending aorta repair in high-risk patients. J Thorac Cardiovasc Surg 2015;149:144-51.

22. Preventza O, Henry MJ, Cheong BYC, et al. Endovascular repair of the ascending aorta: When and how to implement the current technology. Ann Thorac Surg 2014;97:1555-60.

23. Metcalfe MJ, Karthikesalingam A, Black SA, et al. The

doi: $10.21037 /$ jovs-20-127

Cite this article as: Boyajian GP, Ghazi A, Kolesnik I, Toursavadkohi S, Ghoreishi M, Taylor B. Thoracic endovascular aortic repair for type A aortic dissection: a promising option for inoperable patients. J Vis Surg 2021;7:37. first endovascular repair of an acute type A dissection using an endograft designed for the ascending aorta. J Vasc Surg 2012;55:220-2.

24. Tsilimparis N, Debus ES, Oderich GS, et al. International experience with endovascular therapy of the ascending aorta with a dedicated endograft. J Vasc Surg 2016;63:1476-82.

25. ClinicalTrials.gov [Internet]. Bethesda (MD): National Library of Medicine (US). 2000 Feb 29 - Identifier NCT02777528, Evaluation of the GORE® TAG® Thoracic Branch Endoprosthesis (TBE Device) in the Treatment of Lesions of the Aortic Arch and Descending Thoracic Aorta (Zone 0/1) (SSB 11-02); 2016 May 19 [cited 2020 March 04]; [About 6 screens]. Available online: https://clinicaltrials.gov/ct2/show/record/NCT02777528? view=record\#wrapper 